American Journal of Cancer Research and Reviews
(ISSN:2577-4425)

\title{
Giant Cell Tumor of Bone, current treatments, and potential
}

\section{therapeutic alternatives}

Estrada-Villaseñor E., ${ }^{1}$ Meneses A., ${ }^{2}$ Valdés-Flores M., ${ }^{3}$ Coutiño-Alcaraz JM., ${ }^{4}$ LinaresGonzález LM., ${ }^{5}$ Olivos Meza A., ${ }^{6}$ Ostoa-Saloma P., ${ }^{7}$ Delgado Cedillo EA., ${ }^{8}$ Landa Solís C. ${ }^{9}$

${ }^{1}$ National Institute of Rehabilitation. Pathology Service. Mexico City, México. ${ }^{2}$ National Cancer Institute. Managing Director. Mexico City, Mexico. ${ }^{3}$ National Institute of Rehabilitation. Assistant Manager Clinical Research in genetic service. Mexico City, México. ${ }^{4}$ National Institute of Rehabilitation. Pathology Service. Mexico City, Mexico. ${ }^{5}$ National Institute of Rehabilitation. Bone Tumors Service. Mexico City, Mexico. ${ }^{6}$ National Institute of Rehabilitation. Arthroscopy Service. Mexico City, México. ${ }^{7}$ Postgraduate degree in Biological Sciences, National Autonomous University of Mexico, University City, Mexico, Mexico City. ${ }^{8}$ National Institute of Rehabilitation. Bone Tumors Service. Mexico City, Mexico. ${ }^{9}$ National Institute of Rehabilitation. Tissue Engineering and Cell Therapy Unit. Mexico City, Mexico.

\section{ABSTRACT}

Giant cell tumor of bone (GCTB) is a primary bone tumor, locally aggressive. For many, a GCTB is considered a tumor with an unpredictable behavior, particularly regarding recurrences, pulmonary implants, and the possibility of primary malignancy. In terms of risk of recurrence, it is known that it is associated with the type of treatment used initially for the GCTB. The greater the number or recurrences, the greater the risk of pulmonary implants, and the greater the risk of malignant degeneration. Therefore, much of the prognosis of this tumor could be related to the type of initial treatment. Hence the importance of the treatment theme. This review includes a comparison between the various modalities for treatment in GCTB, considering the advantages and disadvantages of each one. Existing GCTB treatments are not $100 \%$ safe and effective at the same time. and this is the reason why the search for other treatment modalities should continue to offer a better oncologic and functional outcome to patients. In the end of this review, based on research work, we also mention other possible therapeutic options that could be explored and used in the future for GCT treatment.

Keywords: Bone tumors, Giant cell tumor of bone, treatment, Denosumab, Bisphosphonates.

*Correspondence to Author: Landa Solís C.

National Institute of Rehabilitation. Tissue Engineering and Cell Therapy Unit. Mexico City, Mexico.

\section{How to cite this article:}

Estrada-Villaseñor E.,Meneses A., Valdés-Flores M., Coutiño-Alcaraz JM.,Linares-González LM., Olivos Meza A., Ostoa-Saloma P., Delgado Cedillo EA., Landa Solís C. Giant Cell Tumor of Bone, current treatments, and potential therapeutic alternatives.American Journal of Cancer Research and Reviews, 2020, 4:13.

\section{escî̀Pub}

eSciPub LLC, Houston, TX USA. Website: https://escipub.com/ 


\section{INTRODUCTION}

A giant cell tumor of bone [GCTB], first described in 1818 by Sir Astley Cooper ${ }^{[1]}$, is a primary bone tumor that is classified as an intermediate, locally aggressive but rarely metastasizing tu- mor ${ }^{[2,3]}$. The frequency of GCTB varies in different countries, being $5 \%$ in the United States of America ${ }^{[4]}, 20 \%$ in China and India ${ }^{[5,6]}$, and $17 \%$ in Mexico. ${ }^{[7]}$ Approximately $80 \%$ of the patients are between 20 and 50 years old, who constitute an economically active population ${ }^{[8]}$.

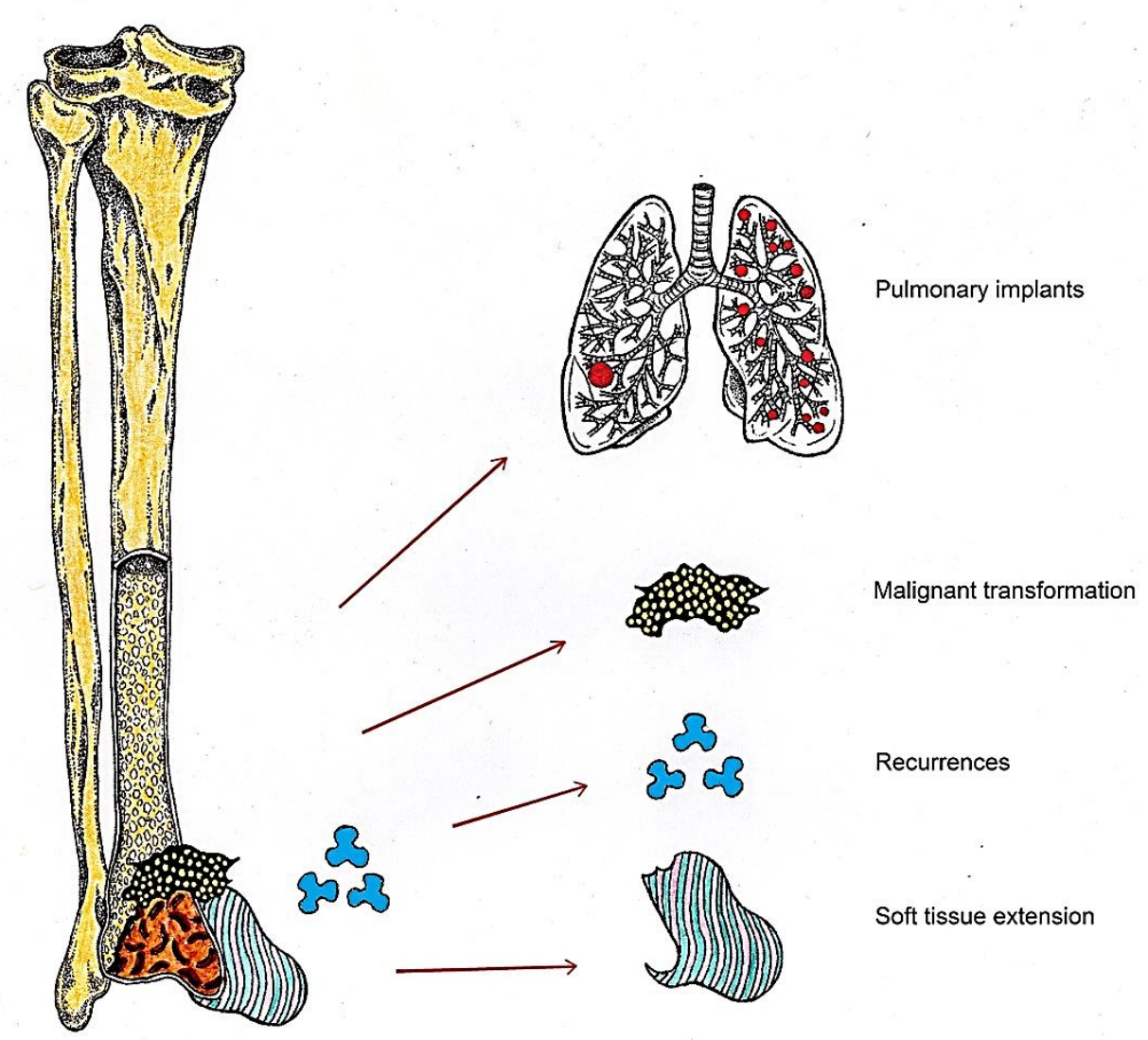

Fig. 1 Clinical presentation of the Giant Cell Tumor of Bone: 1]it can be only in the bone, 2] it can present wide spread to adjacent soft tissues, 3] one or multiple recurrences, 4] single or multiple lung implants or 5] malignant transformation.

GCTB are considered tumors with an unpredictable and varied behavior ${ }^{[9]}$, which can range from being just confined and limited to the bone, to extensive bone destruction, cortical expansion, invasion into soft tissues, one or multiple recurrences ${ }^{[10]}$, lung implants or even malignant transformation[Fig. 1] $]^{[11]}$. In terms of risk of recurrence, it is known to be associated with the type of treatment used initially for the GCTB ${ }^{[12]}$, and Campanacci's grade ${ }^{[13,14]}$. The surgery methods and soft tissue extension are potential risk factors for local recurrence .Recurrences lead to more aggressive surgical interventions and more complications. Hence the relevance of treatment topic, and the reason for our literature review on various modalities of treatment in GCTB.

It is not possible to apply the same treatment for all the GCTB. In order to choose between the different treatment modalities, orthopedic oncologist must consider, principally, the location and the size of the tumor. Although, the initial clinical presentation [lung metastases or presence of recurrence], histology, the functional and oncologic outcome after the treatment choosen, secondary effects, and the patient's desire, are also taken into account in the treatment decision. 
The purpose of this article is to provide an overview of the existing treatments for GCTB, with its advantages, disadvantages, and points where a consensus in missing. We also mention possible therapeutic options that have been underutilized.

\section{TREATMENTS FOR GCTB}

Studies have shown that treatments for GCTB were classified into three groups: 1] Surgical treatment, 2] Complementary therapies and, 3] Underexplored and novel therapies.

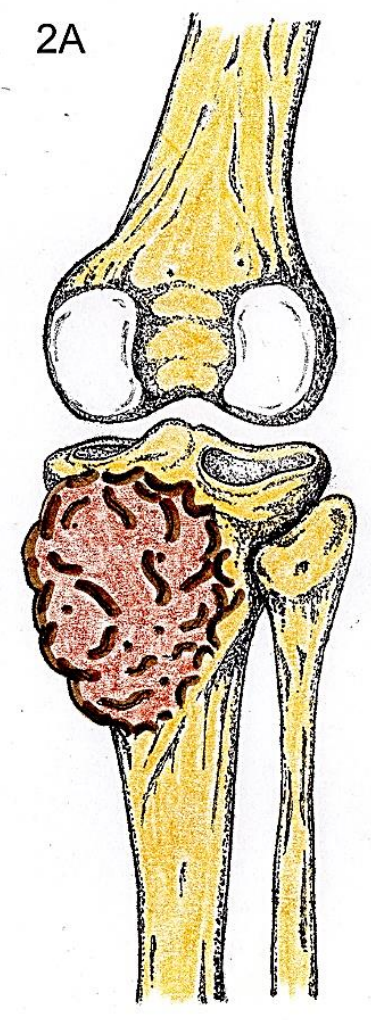

\section{1) Surgical Treatment}

Surgical treatment is considered the major treatment modality for GCTB. The goal of surgical treatment is the complete removal of the tumor, to preserve the function of the affected zone, and to avoid local recurrences that may lead to more surgeries. The surgical treatment of GCTB consists of two main procedures: en bloc resection and curettage.

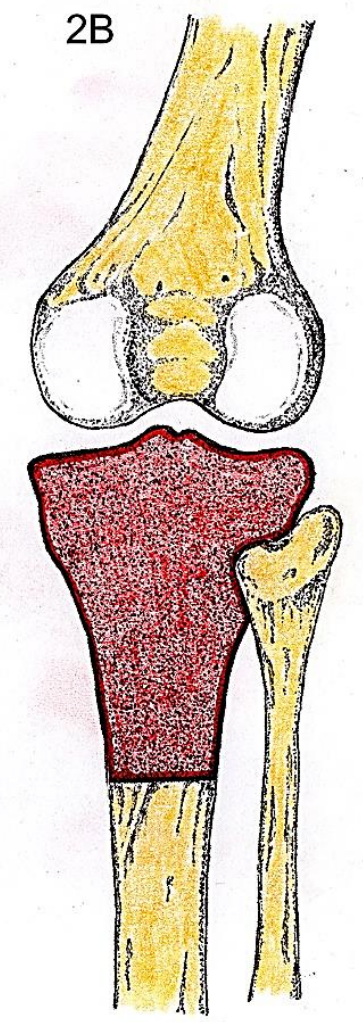

Fig. 2 Giant cell tumor of bone located in the proximal tibia [2A]. A representation of an en block resection of proximal tibia performed for the treatment of GCTB [2B].

En bloc resection: En bloc resection consists of removing the entire bone segment that contains the tumor, thus leaving a safety margin of healthy bone [Fig. 2]. After this treatment, although the tumor margins are free from a tumor, a bone defect [bone absence] is generated. So this procedure is usually followed by a reconstruction [regularly, a prosthesis] ${ }^{[15]}$.

This type of treatment is suggested: 1] when the tumor extends beyond the cortex and destroys it, by extending into the soft tissues; 2] in the presence of pathological fracture; 3] when the articular surface has collapsed or it is impossible to preserve it; 4] after a previous ineffective surgery; or 5] when the GCTB has been diagnosed to be malignant after a histological diagnosis ${ }^{[16]}$.

\section{Curettage:}

This procedure is also known as intralesional excision and it is the most widely used surgical treatment for GCTB. It involves the creation of a bone window through which the intramedullary tumor is scraped to be removed [Fig. 3]. When the preservation of bone architecture or joint is 
desired, intralesional excision, or curettage, is the most preferred procedure for this kind of tumor ${ }^{[16]}$. However, tumor margins are unknown with this treatment and microscopic tumor can be left behind, which may lead to subsequent recurrences. After the tumor has been removed, the cavity can be left unfilled or it can be filled with cement or bone grafting.

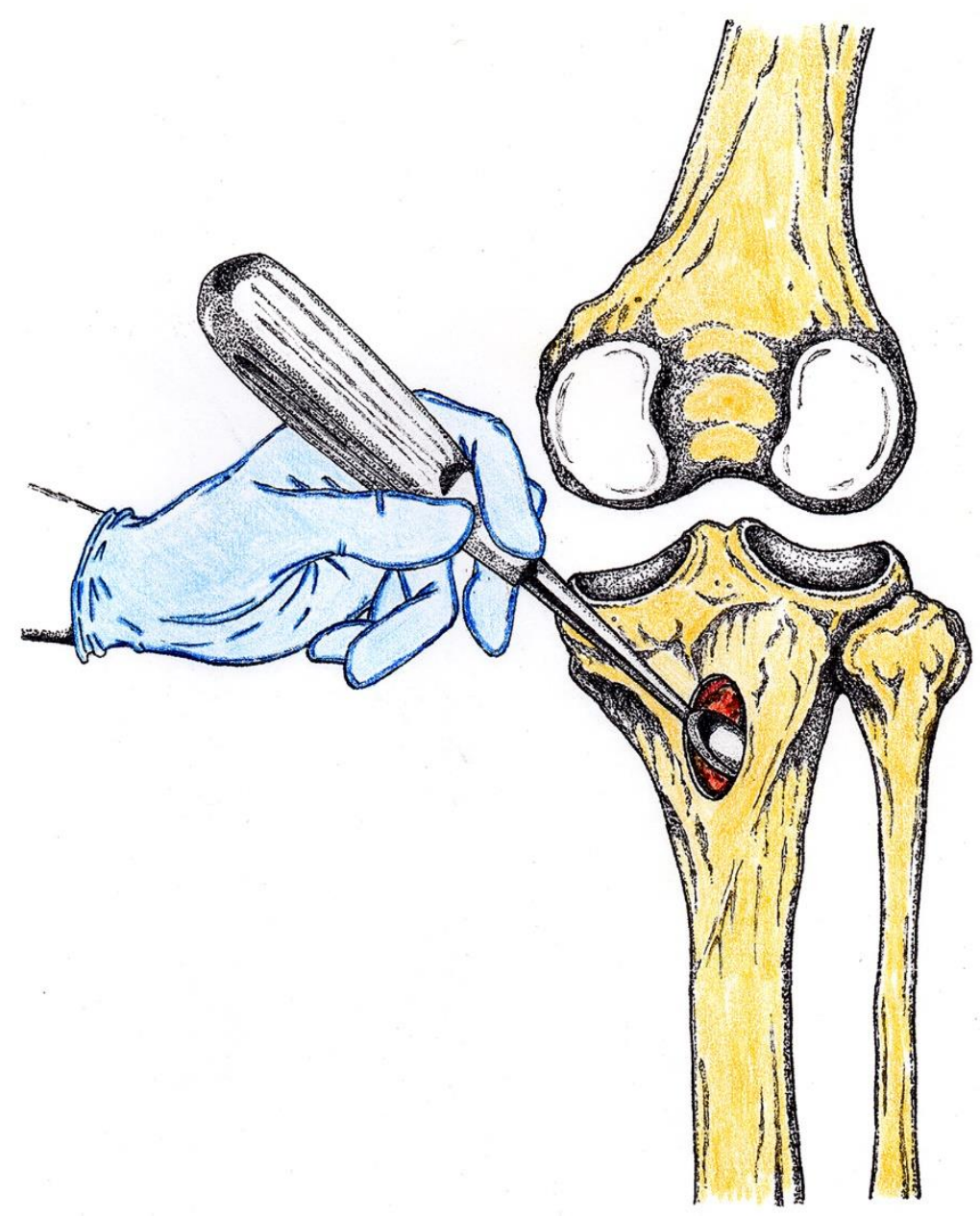

Fig. 3 In bone curettage a cortical hole is made, it is called a bone window. Through this, a curette is introduced in order to extract and remove all the visible tumor.

In order to reduce recurrences, curettage can be accompanied by adjuvants such as phenol, liquid nitrogen, high-speed burr, hydrogen peroxide, or methyl methacrylate. These adjuvants can be used individually or in combination ${ }^{[17]}$.

\section{2) Complementary Therapies}

Even though surgery remains the treatment of choice, carrying it out in certain locations such as spine, sacrum or pelvic bones, involves the risk of damaging nerve roots or nearby structures such as the bladder or colon. Due to the risk of these complications, non-surgical therapies are carried out, and include denosumab, selective arterial embolization, radiotherapy, bisphosphonates, and interferon. Usually, these therapies are used as adjuvant treatment.

\section{Denosumab}

Denosumab, a human monoclonal antibody with an affinity for RANKL, blocks bone resorption by binding to RANKL, and preventing its interaction with RANK, a cell surface receptor on pre-osteoclasts and osteoclasts, thus inhibiting osteoclastogenesis ${ }^{[18]}$. After the open-label, Phase 2 study reported by Thomas et al., ${ }^{[19]}$ denosumab was approved as a therapy for GCTB.

Denosumab administration can modify the initial surgical treatment planned for GCTBs because it reduces the tumor size, and decreases the soft 
tissue component. Patients that receive denosumab preoperatively, may not require an enbloc resection of the tumor, and can be treated with curettage, which preserves the joint and articular surface ${ }^{[20,21]}$. Additionally, denosumab stops bone lysis, promotes tumor sclerosis, and peripheral new bone formation.
Current indications for the use of denosumab in GCTB include lesions in the spine, sacrum, pelvis, and challenging lesions in upper and lowerextremity locations ${ }^{[22]}$.

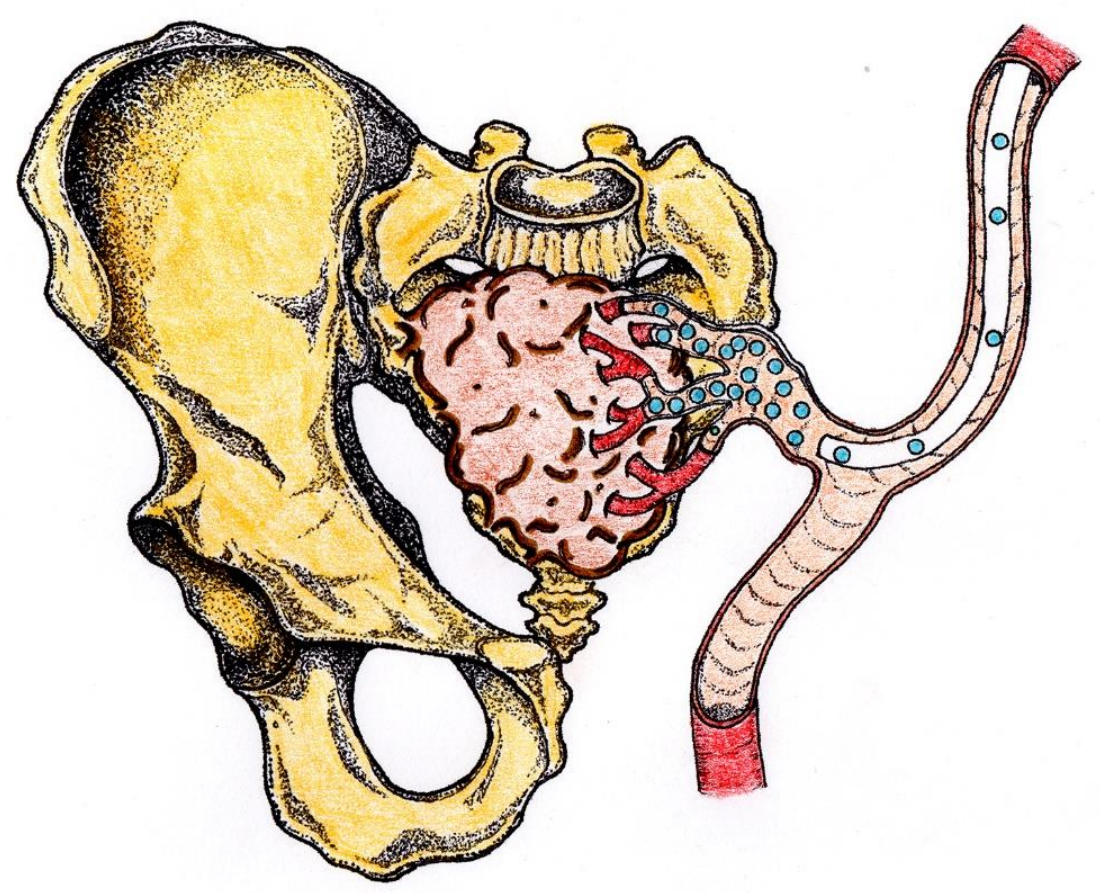

Fig. 4 This is an example of a GCTB located in the sacrum, in which SAE was the treatment or choice. In SAE, the blood supply of the tumor is obstructed embolizing the main arteries that feed the tumor.

\section{Selective Arterial Embolization}

For GCTB that are unresectable due to their location, such as sacrum, selective arterial embolization [SAE] can be used as the initial treatment. SAE has been used for the treatment of giant cell tumors of the sacrum since 1975 with positive results ${ }^{[23]}$. In SAE the main arteries that feed the tumor are selectively embolized, after identifying and selecting the arteries with the help of angiography. The objective of SAE is to occlude the blood supply to the tumor, to stop its growth and allow, in case it is required or decided, a subsequent surgery with minimal bleeding [Fig. 4]. Generally, Gelfoam or morselized polyvinyl alcohol particles are used for peripheral occlusion and stainless steel coils for central occlusion ${ }^{[24]}$. Subsequent embolizations are performed until there is no evidence of collateral circulation ${ }^{[25]}$.

The observed and reported effects of SAE on GCTB are tumor size reduction, relief of symptoms [such as pain], and tumor ossification induction ${ }^{[26]}$. SAE is usually used as a preoperative adjuvant treatment. However, there are case reports and case series of GCTB in the sacrum, in which SAE was the only therapy used ${ }^{[27]}$.

\section{Radiotherapy}

Of all the treatments available for GCTB, radiotherapy [RT] probably is the most controversial modality. This controversy has been existing for many years and originated with the publication 
of cases with malignant transformation or severe osteoradionecrosis, and osteomyelitis after radiotherapy ${ }^{[28]}$. Most of those published cases were from the '40s, in which generally orthovoltage of unknown intensity was used ${ }^{[29]}$. As a result, radiotherapy was avoided in the past, for the treatment of GCTB. Nowadays megavoltage machines are used for RT that lead to the possibility of applying doses with less toxicity, along with sparing of healthy bone and vital structures ${ }^{[30]}$.

At present, radiotherapy [RT] has been used either postoperatively, or as a sole treatment in GCTBs, and is considered an alternative treatment in tumors with difficult surgical access, such as the spine ${ }^{[31]}$. Radiation therapy has also proven to be an effective sole treatment especially for tumors smaller than $4 \mathrm{~cm}$ in diameter and located in long bones, such as the femur, but not in larger tumors ${ }^{[32]}$.

\section{Bisphosphonates}

Bisphosphonates [BPs] have an affinity for hidroxiapatite crystals [HAP]. During bone resorption carried out by the osteoclast, the acidic $\mathrm{pH}$ in the resorption lacuna promotes dissociation of BPs from HAP. This is followed by endocytosis of BPs. In cytosol, nitrogen-containig BPs [NBPs]inhibit the farnesyl pyrophosphate synthase [FPPS] and consequently the biosynthesis of cholesterol and other sterols. On the other hand, non-nitrogen-containing bisphosphonates [nonN-BPs] incorporate into analogs of adenosine triphosphate [aATP] affecting mitochondrial permeability and initiating caspase activation, causing apoptosis of osteoclasts [Fig. 5] ${ }^{[33]}$.

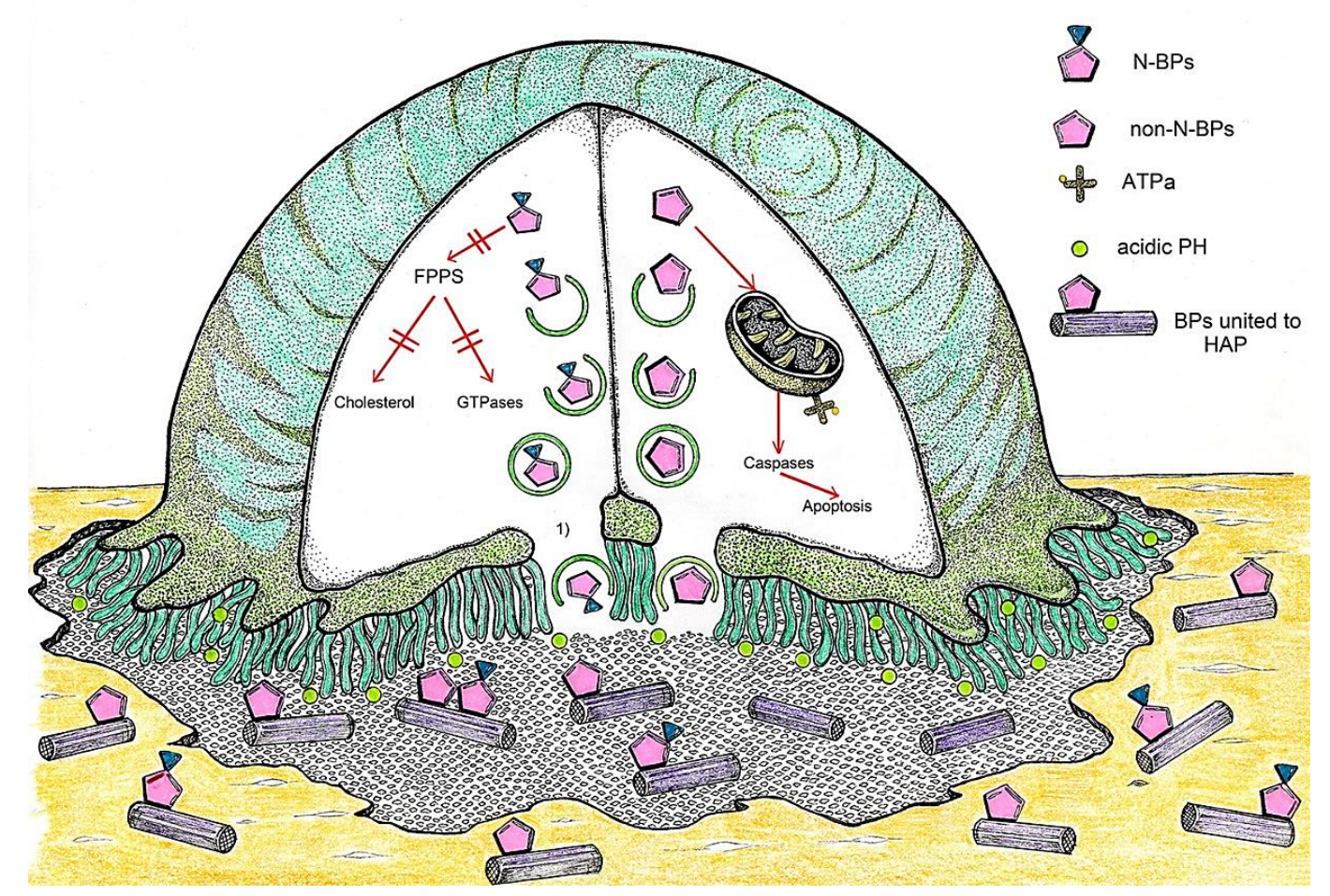

Fig. 5 Mechanism of action of the bisphosphonates in the osteoclast: endocytosis of the bisphosphonates by the osteoclast; N-BPs nitrogen containing bisphosphonates; Non-N-BPs non-nitrogen containing bisphosphonates; FPPS enzyme farnesyl pyrophosphate synthase; HAP hydroxyapatite crystals: ATPa analogs of adenosine triphosphate

Although bisphosphonates are still considered to be exploratory in GCTB therapy, their efficacy has been demonstrated in vitro ${ }^{[34]}$, in vivo ${ }^{[35]}$, and in patients ${ }^{[36-38]}$. There are several reports regarding its use in GCTB, mainly as an adjuvant, that demonstrate its effects from the clinical, radiological, and histological point of view. Preoperative administration of BPs can reduce tumor size and prevent surgical dissemination. 
The clinical response with BPs consists of a reduction of pain. The radiological changes consist of increased radiodensity within the lesion and in the periphery. BPs decrease the rate of tumor progression, and the rate of local bone destruction with no changes in tumor volume. Light microscopic examination performed after bisphosphonate therapy, shows an increase in apoptosis figures. Ultrastructural observations of specimens following bisphosphonates therapy, report pyknosis, nuclear fragmentation, and formation of blebs in the nuclear membrane ${ }^{[39]}$.

\section{Interferon}

Interferon-alpha 2a inhibits angiogenesis ${ }^{[40]}$. Initially, it was reported to be effective in the case of generalized GCTB with pulmonary metasta$\operatorname{ses}^{[41]}$. Later on, Interferon-alpha 2a was also reported as a stand-alone treatment in two cases of unresectable, recurrent, and metastatic giant cell tumors, originating from the spine ${ }^{[42]}$.

In the case of GCTB, interferon treatment is usually accepted as the last option for GCTB when other therapies such as SAE, surgery, and radiotherapy fail in treating the tumor ${ }^{[41,42] \text {. }}$

It is not a standard therapeutic agent for GCTB.

\section{3) Underexplored and novel therapies}

Navigation guided En Bloc Resection is a novel technique. In this procedure, an osteotomy is carried out. Before performing the osteotomy, CT scans and MRI images are fused and used to determine tumor location, extension, and limits between tumor and uncompromised bone. With this technique, minimum healthy bone is removed along with the tumor and it is made sure that the surgical margins are free from any cancer cells ${ }^{[43]}$. There is one study in which this procedure was used in GCTB ${ }^{[44]}$.

\section{Bisphosphonate-loaded bone cement}

There is a study in which the bone cement that was used to fill the osseous defect left by the curettage in GCTB, was loaded with bisphosphonate as adjuvant therapy for GCTB ${ }^{[45]}$. The follow-up of this study was performed for 1 to 12 years and only one local recurrence was reported with this therapy. The authors mention in their work that BP-loaded polymethylmethacrylate is a targeted local adjuvant therapy that is feasible, safe, and may reduce local recurrences while alleviating the risk of systemic side effects caused when BPs are administered systemically.

\section{WHICH TREATMENT IS SAFEST FOR THE PATIENT?}

The purposes of GCTB treatments are: 1] to eradicate the tumor, 2] to preserve function, and 3 ] to generate the least amount of secondary effects in the patient. However, these 3 objectives cannot be always achieved in the same proportion.

En bloc resection: Although low recurrence, and reoperation rates are associated with en bloc resection[oncologic outcome] as compared to intralesional excision ${ }^{[46]}$, this is not the first surgical option due to its functional limitations. With this type of treatment, depending on the location of the tumor, recurrences range from $0 \%$ to $5 \%$. This treatment is followed by a major reconstruction procedure with complications related to the implant such as prosthetic subluxation, prosthetic loosening, necrosis, and infections associated with the extension of the surgery, which may lead to repeated surgery. Functional limitations with this type of treatment are greater as compared to curettage, according to studies reported by several authors ${ }^{[47,48]}$.

Curettage: Curettage is the surgery of choice for GCTB. However, the recurrence rate with sole curettage is higher as compared to that observed in the case of en bloc resection and ranges from $40 \%$ to $65 \%[49]$. Curettage is the preferred surgical option because as compared to en bloc resection, it has fewer complications, better functional results, and preserves the joint. To reduce the recurrence rate, curettage can be accompanied by adjuvants such as phenol, liquid nitrogen, high-speed burr, hydrogen peroxide, or methyl methacrylate ${ }^{[50]}$. However, there is no consensus about indications for the different adjuvants available ${ }^{[51]}$. The local recurrence rate following curettage and high-speed burr is lower than that following sole curettage. The use of 
high speed burring with another adjuvant also shows additional effects ${ }^{[52]}$. Curettage when carried out in combination with phenol, shows a recurrence rate of $19 \%$, with liquid nitrogen it shows a rate of $21 \%$, with hydrogen peroxide the rate is evaluated to be $22 \%$, with methyl methacrylate it exhibits a rate varying from $0-29 \%$, and with phenol and methyl methacrylate the rate varies from $0-33 \%[53,54]$. The lowest recurrence rate of $6 \%$ has been reported when liquid nitrogen and methyl methacrylate were used together ${ }^{[55-57]}$.

With the use of adjuvants, there is a significant decrease from $65 \%$ to $6 \%$ in the recurrence rate, as compared to when sole curettage was performed. Some adjuvants seem to be more efficient than others.

\section{Denosumab:}

There is controversy about the use of denosumab in GCTB because earlier studies reported an excellent clinical effect of denosumab on GCTB. However, a recent study shows that denosumab may increase the risk of local recurrence in patients treated with curettage, and in the histopathological evaluation of the samples viable tumor was observed[58]. On the other hand, a systematic review that evaluated local recurrence rate, and development of lung metastasis in patients treated with denosumab, reported a neutral effect of denosumab on the metastatic rate of GCTB, and a recurrence rate similar to that observed after using extended curettage ${ }^{[59]}$. Also, researchers have reported that $40 \%$ of patients discontinuing denosumab for GCTB have tumor progression after a median of 8 months $^{[60]}$. In adittion, it is necessary to have a consensus regarding 1] the number of doses, and the treatment length, which may vary from 4 months to 55 months, and 2] the criteria for continuation or discontinuation of denosumab treatment. Furthermore, it is added the fact that there is a risk of malignant transformation ${ }^{[61]}$.

\section{Selective arterial embolization}

The complications reported after SAE are neurological such as unilateral weakness of ankle dorsiflexion and transient numbness in the great toe.

A small amount of data has been published to date on the long-term follow-up of GCTB patients who have undergone selective arterial embolization. In the study conducted by Lin PP. et al., $65 \%$ of the patients did not show any evidence of progressive disease in the sacrum after 5 years of the treatment. After 10, 15, and 20 years, $57 \%$ of patients did not have any disease progression ${ }^{[62]}$.

For some authors, the number of embolizations sessions is based on clinical cymptoms, radiographic response, and the vascularity of the tumor, therefore five embolizations are performed on an average. However, the SAE interval mentioned in related articles is not consistent and ranges from three to eight weeks. Standard guidelines are necessary for SAE in the case of GCTB regarding the number of embolizations, the interval between the sessions, and the proper time of stopping the treatment ${ }^{[25]}$.

\section{Radiotherapy:}

Malignant transformation continues to be a feared secondary effect, although recent studies do not report this complication ${ }^{[63]}$.

There are two studies that analyze patient cohorts undergoing treatment with RT for GCTB. The first study, reports that the cases undergoing irradiation for recurrent GCTB had worse prognosis than the primary GCTB cases ${ }^{[64]}$. In the second report, it was found that the axial location showed a negative influence on local progression-free survival when compared with the GCTB cases of appendicular location ${ }^{[31]}$.

In the systematic review of Ma Y. et al, radiotherapy was evaluated in GCTB located in the spine. In this study, all patients received megavoltage and, exhibited a response to RT. In those patients who presented local failure within the two years after radiotherapy, the overall survival was $97.6 \%$, and the overall local control was $79 \%$. In this systematic review, post-RT neurological complications were present in $9 \%$ of the patients. There were no cases with malignant 
transformation. The difference between the effects of orthovoltage and megavoltage with respect to the local failure, as reported in previous studies was also discussed in this article, which varies from $7 \%$ to $30 \%$ with megavoltage and as high as $63 \%$ with orthovoltage ${ }^{[65]}$.

\section{Bisphosphonates:}

The secondary effects reported with BPs in patients with GCTB were a decrease in calcium levels, jaw osteonecrosis, fever and digestive upset. ${ }^{\left[{ }^{[5]}\right.}$ Apparently, the type of bisphosphonate and previous dental procedures, may act as precipitating factors for jaw osteonecrosis ${ }^{[66]}$.

BPs reduce the recurrence rate when administered after and before the surgery. The benefit reported when using BPs before surgical procedures [such as curettage] in extremities, is a decrease in recurrence rate as compared to the rate when sole surgical treatment is carried out, being $4.2 \%$ with $\mathrm{BPs}$ and $30 \%$ without BPs. ${ }^{[37,38]}$ Apparently, there is no prognosis difference in patients who receive BPs before or after a surgical procedure, since both types of patients show positive outcomes to the treatment.

The studies that report atypical fractures are in patients receiving long-term [10 years] bisphosphonate therapy ${ }^{[67]}$. BPs are not administered for so long in GCTB patients. In the case of jaw osteonecrosis, the length of exposure seems to be the most important risk factor for this complication $^{[68,69]}$, which has an average exposure time of 39 months.

If further research is conducted, routine use of bisphosphonates may become a standard for the adjuvant treatment of GCTB.

\section{Navigation guided En Bloc Resection:}

The use of this surgical alternative has not been proved accurately in GCTB. This technique results in more precise resections in order to obtain free margins, which are necessary to avoid local recurrences. In the bone tumor cases, treated with this modality, no recurrences have been reported ${ }^{[44]}$. When compared with curettage, no differences are found in postoperative complications and functional scores, in the case of both procedures. Patients undergoing this treatment might attain the benefit of a lower risk of recurrence without compromising the function. However, this procedure has been reported to increase surgical time and is expensive. Further studies are required to compare the costbenefit of navigation-guided en bloc resection against repeated curettages or more extensive surgeries secondary to recurrences.

\section{Bisphosphonate-loaded bone cement}

This modality is novel and may be promising because bisphosphonates are administered only locally, in a lesser amount than when administered systemically, avoiding in this way the secondary and systemic effects ${ }^{[45]}$. However, the indications for its application would be very specific, since it can only be used after curettage. Further studies are required as there is too little literature on the subject to discuss.

\section{SUMMARY}

The objectives of this review were to provide an overview of the existing treatments for GCTB, with its advantages, disadvantages, and indications, and also to mention possible therapeutic options that have been underutilized. During the conduct of this study, we found certain aspects of some treatments in which consensus is needed, and decided to mention them. At the end of this investigation, we can mention that although all the treatments have advantages, and disadvantages at the same time [Table 1], there is always a possibility of improving them. Thus, we conclude that we have not reached the endpoint of the process of exploring GCTB therapy.

\section{Key Points}

- GCTB is considered a tumor with an unpredictable behavior, with recurrences, pulmonary implants, and the possibility of primary malignancy.

- The treatments for GCTB were classified into three groups: 1] Surgical treatment, 2] Complementary therapies and, 3] Underexplored and novel therapies. 
- All the GCTB treatments have advantages, and disadvantages at the same time, but it exists the possibility of improving them and develop new therapeutic strategies.

\section{Ethics approval and consent to participate}

Ethical approval for the study was not required, this article does not contain any studies performed on human participants, or animals, by any of the authors.

\section{ACKNOWLEDGEMENTS}

We thanks David Quintero for the English language, grammar, punctuation, spelling and overall style, and Agustín Acosta Vargas for the figures design.

\section{CONFLICT OF INTEREST DISCLOSURES}

We have read and understood Current Oncology's policy on disclosing conflicts of interest, and we declare that we have none.

\section{AUTHOR AFFILIATIONS}

"Pathology Service. National Institute of Rehabilitation, Mexico City, México. ${ }^{\dagger}$ General management. National Cancer Institute, Mexico City, México. $¥$ Genetic service. National Institute of Rehabilitation, Mexico City, México. \$Bone Tumors Service. National Institute of Rehabilitation, Mexico City, México. "Arthroscopy Service. National Cancer Institute, Mexico City, México. \#Postgraduate degree in Biological Sciences, National Autonomous University of Mexico, University City, Mexico City, Mexico. ${ }^{* *}$ Tissue Engineering and Cell Therapy Unit. National Institute of Rehabilitation, Mexico City, México.

Table 1 Treatment Modalities for Giant Cell Tumor of bone. Advantages and disadvantages

\begin{tabular}{|c|c|c|c|}
\hline TREATMENT & ADVANTAGES & DISADVANTAGES & REFERENCES \\
\hline En bloc resection & $\begin{array}{l}\text { Surgical margins free } 0- \\
5 \% \text { recurrences }\end{array}$ & Functional limitations & $\begin{array}{l}\text { Jamshidi et al. } \\
{[2018]}\end{array}$ \\
\hline Curettage & $\begin{array}{l}\text { Preserves the joint and } \\
\text { good functional outcome }\end{array}$ & $\begin{array}{l}\text { Tumor margins unknown and } \\
\text { recurrence rate } 40-60 \%\end{array}$ & Wysocki et al. [2015] \\
\hline Selective Arterial Embolization & $\begin{array}{l}\text { An option for GCT difficult } \\
\text { to access }\end{array}$ & $\begin{array}{l}\text { Tissue necrosis of the affected } \\
\text { region }\end{array}$ & Emori et al [2012] \\
\hline Radiotherapy & $\begin{array}{l}\text { An alternative for unre- } \\
\text { sectable GCT }\end{array}$ & $\begin{array}{l}\text { Neurological complications in } \\
9 \% \text { of the cases }\end{array}$ & Ma et al. [2015] \\
\hline Biphosphonates & $\begin{array}{l}\text { Reduce recurrence rate } \\
\text { to } 4.2 \%\end{array}$ & $\begin{array}{l}\text { Secondary effects: fever and } \\
\text { digestive upset }\end{array}$ & Xu et al [2017] \\
\hline Denosumab & $\begin{array}{l}\text { Useful in unresectable } \\
\text { GCT }\end{array}$ & $\begin{array}{l}\text { Tumor progression in } 40 \% \text { of } \\
\text { the cases after discontinuation }\end{array}$ & Palmerini et al [2017] \\
\hline Interferon & $\begin{array}{l}\text { An option for GCT in } \\
\text { which other therapies } \\
\text { have failed }\end{array}$ & No data reported & Wei et al [2010] \\
\hline
\end{tabular}

\section{References}

1. McCarthy EF. Giant-cell tumor of bone: an historical perspective. Clin Orthop Relat Res. 1980[153]:14-25.

2. Jo VY, Fletcher CD. WHO classification of soft tissue tumours: an update based on the 2013 [4th] edition. Pathology. 2014;46[2]:95-104. 10.1097/pat.0000000000000050

3. Roessner A, Smolle M, Haybäck J. [Giant cell tumor of bone : Morphology, molecular pathogenesis, and differential diagnosis]. Pathologe. 2020;41[2]:134-42. 10.1007/s00292-020-00760-5

4. Harrleson J. Bone tumors: general aspects and data on 6,221 cases. Annals of Surgery. 1980;191[4]:511.

5. Jain K, Sunila RR, Mruthyunjaya C, Gadiyar H, Manjunath $\mathrm{G}$. Bone tumors in a tertiary care hospital of south India: A review 117 cases. Indian journal of medical and paediatric oncology: official journal of Indian Society of Medical \& Paediatric Oncology. 2011;32[2]:82. 
6. Liede A, Hernandez RK, Tang E-T, Li C, Bennett $\mathrm{B}$, Wong SS, et al. Epidemiology of benign giant cell tumor of bone in the Chinese population. Journal of bone oncology. 2018;12:96-100.

7. Estrada-Villaseñor E, Linares-González L, Delgado-Cedillo E, González-Guzmán R, RicoMartínez G. Prevalencia y características clínicopatológicas del tumor de células gigantes. Acta ortopédica mexicana. 2015;29[6]:295-8.

8. Niu X, Xu H, Inwards CY, Li Y, Ding Y, Letson GD, et al. Primary bone tumors: epidemiologic comparison of 9200 patients treated at Beijing Ji Shui Tan hospital, Beijing, China, with 10165 patients at Mayo Clinic, Rochester, Minnesota. Archives of Pathology and Laboratory Medicine. 2015;139[9]:1149-55.

9. Yang Y, Huang Z, Niu X, Xu H, Li Y, Liu W. Clinical characteristics and risk factors analysis of lung metastasis of benign giant cell tumor of bone. J Bone Oncol. 2017; 7: 23-8.

10. Klenke FM, Wenger DE, Inwards CY, Rose PS, Sim FH. Giant cell tumor of bone: risk factors for recurrence. Clinical Orthopaedics and Related Research®. 2011;469[2]:591-9.

11. Alberghini $M$, Kliskey $K$, Krenacs $T$, Picci $P$, Kindblom L, Forsyth R, et al. Morphological and immunophenotypic features of primary and metastatic giant cell tumour of bone. Virchows Archiv. 2010;456[1]:97-103.

12. Li D, Zhang J, Li Y, Xia J, Yang Y, Ren M, et al. Surgery methods and soft tissue extension are the potential risk factors of local recurrence in giant cell tumor of bone. World journal of surgical oncology. 2016;14[1]:114.

13. Cheng D-d, Hu T, Zhang H-z, Huang J, Yang Qc. Factors affecting the recurrence of giant cell tumor of bone after surgery: a clinicopathological study of 80 cases from a single center. Cellular Physiology and Biochemistry. 2015;36[5]:1961-70.

14. Teixeira L, Vilela J, Miranda RH, Gomes AH, Costa FA, de Faria VC. Giant cell tumors of bone: nonsurgical factors associated with local recurrence. Acta Orthop Traumatol Turc. 2014;48[2]:136.

15. Rico-Martínez G, Linares-González L, DelgadoCedillo E, Espejo-Sánchez G, Cerrada-Moreno L, Clara-Altamirano $M$. Long-term results of the treatment of a giant cell tumor with en-bloc resection and unconventional hip arthroplasty with ipsilateral knee arthrodesis. Clinical case report and literature review. Acta Ortopédica Mexicana. 2013;27[4]:250-5.

16. Saini R, Bali K, Bachhal V, Mootha AK, Dhillon MS, Gill SS. En bloc excision and autogenous fibular reconstruction for aggressive giant cell tumor of distal radius: a report of 12 cases and review of literature.
Journal of orthopaedic surgery and research. 2011;6[1]:14.

17. Knochentumoren A. Local recurrence of giant cell tumor of bone after intralesional treatment with and without adjuvant therapy. JBJS. 2008;90[5]:1060-7.

18. Hsu H, Lacey DL, Dunstan CR, Solovyev I, Colombero A, Timms E, et al. Tumor necrosis factor receptor family member RANK mediates osteoclast differentiation and activation induced by osteoprotegerin ligand. Proceedings of the National Academy of Sciences. 1999;96[7]:3540-5.

19. Thomas D, Henshaw R, Skubitz K, Chawla S, Staddon A, Blay J-Y, et al. Denosumab in patients with giant-cell tumour of bone: an open-label, phase 2 study. The lancet oncology. 2010;11[3]:275-80.

20. Rutkowski P, Ferrari S, Grimer RJ, Stalley PD, Dijkstra SP, Pienkowski A, et al. Surgical downstaging in an open-label phase II trial of denosumab in patients with giant cell tumor of bone. Annals of surgical oncology. 2015;22[9]:2860-8.

21. Traub F, Singh J, Dickson BC, Leung $S$, Mohankumar R, Blackstein ME, et al. Efficacy of denosumab in joint preservation for patients with giant cell tumour of the bone. European Journal of Cancer. 2016;59:1-12.

22. Thornley P, Habib A, Bozzo A, Evaniew N, Ghert $M$. The role of denosumab in the modern treatment of giant cell tumor of bone. Jbjs Reviews. 2017;5[4].

23. FELDMAN F, CASARELLA WJ, DICK HM, HOLLANDER BA. Selective intra-arterial embolization of bone tumors: a useful adjunct in the management of selected lesions. American Journal of Roentgenology. 1975;123[1]:130-9.

24. Nakanishi K, Osuga K, Hori S, Hamada K, Hashimoto N, Araki N, et al. Transarterial embolization [TAE] of sacral giant cell Tumor [GCT] using spherical parmanent embolic material superabsorbant polymer microsphere [SAP-MS]. Springerplus. 2013;2[1]:666.

25. Hosalkar HS, Jones KJ, King JJ, Lackman RD. Serial arterial embolization for large sacral giant-cell tumors: mid-to long-term results. Spine. 2007;32[10]:1107-15.

26. He Sh, Xu W, Sun Zw, Liu Wb, Liu Yj, Wei Hf, et al. Selective arterial embolization for the treatment of sacral and pelvic giant cell tumor: a systematic review. Orthopaedic Surgery. 2017;9[2]:139-44.

27. Onishi H, Kaya M, Wada T, Nagoya S, Sasaki M, Yamashita T. Giant cell tumor of the sacrum treated with selective arterial embolization. International journal of clinical oncology. 2010;15[4]:416-9.

28. Stewart FW, Coley BL, Farrow JH. Malignant giant cell tumor of bone. The American journal of pathology. 1938;14[5]:515. 
29. Ellis F. Treatment of osteoclastoma by radiation. The Journal of bone and joint surgery British volume. 1949;31[2]:268-80.

30. Chakravarti A, Spiro IJ, Hug EB, Mankin HJ, Efird JT, Suit HD. Megavoltage radiation therapy for axial and inoperable giant-cell tumor of bone. JBJS. 1999;81[11]:1566-73.

31. Ruka W, Rutkowski P, Morysiński T, Nowecki Z, Zdzienicki M, Makula D, et al. The megavoltage radiation therapy in treatment of patients with advanced or difficult giant cell tumors of bone. International Journal of Radiation Oncology* Biology* Physics. 2010;78[2]:494-8.

32. Miszczyk L, Wydmański J, Spindel J. Efficacy of radiotherapy for giant cell tumor of bone: given either postoperatively or as sole treatment. International Journal of Radiation Oncology* Biology* Physics. 2001;49[5]:1239-42.

33. Russell R, Watts $N$, Ebetino $F$, Rogers $M$. Mechanisms of action of bisphosphonates: similarities and differences and their potential influence on clinical efficacy. Osteoporosis international. 2008;19[6]:73359.

34. Chang SS, Suratwala SJ, Jung KM, Doppelt JD, Zhang $\mathrm{HZ}$, Blaine TA, et al. Bisphosphonates may reduce recurrence in giant cell tumor by inducing apoptosis. Clinical Orthopaedics and Related Research®. 2004;426:103-9.

35. Shibuya I, Takami M, Miyamoto A, Karakawa A, Dezawa A, Nakamura $S$, et al. In vitro study of the effects of denosumab on giant cell tumor of bone: comparison with zoledronic acid. Pathology \& Oncology Research. 2019;25[1]:409-19.

36. Chaudhary P, Khadim H, Gajra A, Damron T, Shah C. Bisphosphonate therapy is effective in the treatment of sacral giant cell tumor. Oncology Research and Treatment. 2011;34[12]:702-4.

37. Tse LF, Wong KC, Kumta SM, Huang L, Chow TC, Griffith JF. Bisphosphonates reduce local recurrence in extremity giant cell tumor of bone: a case-control study. Bone. 2008;42[1]:68-73.

38. Xu W, Wang Y, Wang J, Yang X, Liu W, Zhou W, et al. Long-term administration of bisphosphonate to reduce local recurrence of sacral giant cell tumor after nerve-sparing surgery. Journal of Neurosurgery: Spine. 2017;26[6]:716-21.

39. Dubey S, Rastogi S, Sampath V, Khan SA, Kumar A. Role of intravenous zoledronic acid in management of giant cell tumor of bone-A prospective, randomized, clinical, radiological and electron microscopic analysis. Journal of Clinical Orthopaedics and Trauma. 2019;10[6]:1021-6.
40. Sidky YA, Borden EC. Inhibition of angiogenesis by interferons: effects on tumor-and lymphocyteinduced vascular responses. Cancer research. 1987;47[19]:5155-61.

41. Kaiser U, Neumann K, Havemann K. Generalised giant-cell tumour of bone: Successful treatment of pulmonary metastases with interferon $\alpha$, a case report. Journal of cancer research and clinical oncology. 1993;119[5]:301-3.

42. Wei F, Liu X, Liu Z, Jiang L, Dang G, Ma Q, et al. Interferon alfa-2b for recurrent and metastatic giant cell tumor of the spine: report of two cases. Spine. 2010;35[24]:E1418-E22.

43. Young PS, Bell SW, Mahendra A. The evolving role of computer-assisted navigation in musculoskeletal oncology. Bone Joint J. 2015;97b[2]:258-64. 10.1302/0301-620x.97b2.34461

44. Farfalli GL, Albergo Jl, Piuzzi NS, Ayerza MA, Muscolo DL, Ritacco LE, et al. Is Navigation-guided En Bloc Resection Advantageous Compared With Intralesional Curettage for Locally Aggressive Bone Tumors? Clinical Orthopaedics and Related Research. 2018;476[3]:511.

45. Greenberg DD, Lee FY. Bisphosphonate-loaded Bone Cement as a Local Adjuvant Therapy for Giant Cell Tumor of Bone. American journal of clinical oncology. 2019;42[3]:231-7.

46. Gitelis S, Mallin BA, Piasecki P, Turner F. Intralesional excision compared with en bloc resection for giant-cell tumors of bone. The Journal of Bone and Joint surgery American Volume. 1993;75[11]:164855.

47. Jamshidi K, Bahrabadi M, Bagherifard A, Mohamadpour M. Surgical treatment outcome of giant cell tumor of distal ulna: En bloc resection vs. curettage and bone graft. Medical journal of the Islamic Republic of Iran. 2018;32:44.

48. Wysocki RW, Soni E, Virkus WW, Scarborough MT, Leurgans SE, Gitelis S. Is intralesional treatment of giant cell tumor of the distal radius comparable to resection with respect to local control and functional outcome? Clinical Orthopaedics and Related Research®. 2015;473[2]:706-15.

49. Errani C, Ruggieri $P$, Asenzio MAN, Toscano A, Colangeli S, Rimondi E, et al. Giant cell tumor of the extremity: a review of 349 cases from a single institution. Cancer treatment reviews. 2010;36[1]:1-7.

50. Errani C, Tsukamoto S, Ciani G, Donati DM. Present day controversies and consensus in curettage for giant cell tumor of bone. Journal of Clinical Orthopaedics and Trauma. 2019;10[6]:101520. 
51. Balke M, Schremper L, Gebert C, Ahrens H, Streitbuerger A, Koehler G, et al. Giant cell tumor of bone: treatment and outcome of 214 cases. Journal of cancer research and clinical oncology. 2008;134[9]:969-78.

52. Dürr $H$, Maier $M$, Jansson $V$, Baur $A$, Refior $H$. Phenol as an adjuvant for local control in the treatment ofgiant cell tumour of the bone. European Journal of Surgical Oncology. 1999;25[6]:610-8.

53. Omlor GW, Lange J, Streit M, Gantz S, Merle C, Germann T, et al. Retrospective analysis of 51 intralesionally treated cases with progressed giant cell tumor of the bone: local adjuvant use of hydrogen peroxide reduces the risk for tumor recurrence. World journal of surgical oncology. 2019;17[1]:73.

54. Saiz P, Virkus W, Piasecki P, Templeton A, Shott $S$, Gitelis $S$. Results of giant cell tumor of bone treated with intralesional excision. Clinical Orthopaedics and Related Research [1976-2007]. 2004;424:221-6.

55. Abdelrahman M, Bassiony AA, Shalaby $H$, Assal MK. Cryosurgery and impaction subchondral bone graft for the treatment of giant cell tumor around the knee. HSS journal. 2009;5[2]:123-8.

56. Alkalay D, Kollender Y, Mozes M, Meller I. Giant cell tumors with intraarticular fracture Two-stage local excision, cryosurgery and cementation in 5 patients with distal femoral tumor followed for 2-4 years. Acta Orthopaedica Scandinavica. 1996;67[3]:291-4.

57. Wittig JC, Simpson BM, Bickels J, Kellar-Graney $\mathrm{KL}$, Malawer MM. Giant cell tumor of the hand: superior results with curettage, cryosurgery, and cementation. The Journal of hand surgery. $2001 ; 26[3]: 546-55$.

58. Scoccianti G, Totti F, Scorianz M, Baldi G, Roselli G, Beltrami G, et al. Preoperative Denosumab with curettage and Cryotherapy in Giant cell tumor of bone: is there an increased risk of local recurrence? Clinical orthopaedics and related research. 2018;476[9]:1783.

59. Luengo-Alonso G, Mellado-Romero M, Shemesh S, Ramos-Pascua L, Pretell-Mazzini J. Denosumab treatment for giant-cell tumor of bone: a systematic review of the literature. Archives of orthopaedic and trauma surgery. 2019;139[10]:1339-49.

60. Palmerini E, Chawla N, Ferrari S, Sudan M, Picci $P$, Marchesi $E$, et al. Denosumab in advanced/unresectable giant-cell tumour of bone [GCTB]: for how long? European Journal of Cancer. 2017;76:118-24.

61. Broehm CJ, Garbrecht EL, Wood J, Bocklage T. Two cases of sarcoma arising in giant cell tumor of bone treated with denosumab. Case reports in medicine. 2015;2015.
62. Lin PP, Guzel VB, Moura MF, Wallace S, Benjamin RS, Weber KL, et al. Long-term follow-up of patients with giant cell tumor of the sacrum treated with selective arterial embolization. Cancer. 2002;95[6]:1317-25.

63. Caudell JJ, Ballo MT, Zagars GK, Lewis VO, Weber KL, Lin PP, et al. Radiotherapy in the management of giant cell tumor of bone. International Journal of Radiation Oncology* Biology* Physics. 2003;57[1]:158-65.

64. Ma Y, Xu W, Yin H, Huang Q, Liu T, Yang X, et al. Therapeutic radiotherapy for giant cell tumor of the spine: a systemic review. European Spine Journal. 2015;24[8]:1754-60.

65. Shi M, Chen L, Wang Y, Wang W, Zhang Y, Yan $S$. Effect of bisphosphonates on local recurrence of giant cell tumor of bone: a meta-analysis. Cancer Management and Research. 2019;11:669.

66. Sedghizadeh PP, Kumar SK, Gorur A, Schaudinn C, Shuler CF, Costerton JW. Microbial biofilms in osteomyelitis of the jaw and osteonecrosis of the jaw secondary to bisphosphonate therapy. The Journal of the American Dental Association. 2009;140[10]:125965.

67. Sellmeyer DE. Atypical fractures as a potential complication of long-term bisphosphonate therapy. Jama. 2010;304[13]:1480-4.

68. Bamias A, Kastritis E, Bamia C, Moulopoulos LA, Melakopoulos I, Bozas G, et al. Osteonecrosis of the jaw in cancer after treatment with bisphosphonates: incidence and risk factors. J Clin Oncol. 2005;23[34]:8580-7.

69. Migliorati CA, Woo S-B, Hewson I, Barasch A, Elting LS, Spijkervet FK, et al. A systematic review of bisphosphonate osteonecrosis [BON] in cancer. Supportive care in cancer. 2010;18[8]:1099-106. 